\title{
Nursing education challenges and solutions in Sub Saharan Africa: an integrative review \\ (1) CrossMark
}

\author{
Thokozani Bvumbwe ${ }^{1 *}$ (D) and Ntombifikile Mtshali ${ }^{2}$
}

\begin{abstract}
Background: The Lancet Commission and the Global Health Workforce Alliance reported that professional education has generally not kept up the pace of health care challenges. Sub Saharan Africa needs an effective and efficient nursing education system to build an adequate, competent and relevant nursing workforce necessary for the achievement of Sustainable Development Goals. The Plan of Action for Scaling up Quality Nursing and Midwifery Education and Practice for the African Region 2012 - 2022 provided a framework for scale up of nurses and midwives. This integrative review examined literature on nursing education challenges and solutions in Sub Saharan Africa to inform development of a model for improving the quality, quantity and relevance of nursing education at local level.

Methods: A search of PubMed, Medline on EBCSOhost and Google Scholar was conducted using key words: nursing education, challenges, solutions and/ or Africa. Published works from 2012 to 2016 were reviewed to explore reports about challenges and solution in nursing education in Sub Saharan Africa. Full texts of relevant studies were retrieved after reading the tittles and abstracts. Critical appraisal was undertaken and the findings of the relevant studies were analysed using thematic analysis.

Results: Twenty articles and five grey sources were included. Findings of the review generally supports World Health Organisation framework for transformative and scale up of health professions education. Six themes emerged; curriculum reforms, profession regulation, transformative teaching strategies, collaboration and partnership, capacity building and infrastructure and resources. Challenges and solutions in nursing education are common within countries. The review shows that massive investment by development partners is resulting in positive development of nursing education in Sub Saharan Africa. However, strategic leadership, networking and partnership to share expertise and best practices are critical.

Conclusion: Sub Saharan Africa needs more reforms to increase capacity of educators and mentors, responsiveness of curricula, strongly regulatory frameworks, and availability of infrastructure and resources. The review adds to the body of knowledge to enhance efforts of stakeholders in the improvement of the quality, quantity and relevance of nursing education in Sub Saharan Africa.
\end{abstract}

\section{Background}

Sub Saharan Africa continues to report poor health indicators with challenged health systems due to growing burden of diseases including HIV/ AIDS and non-communicable diseases and a severe shortage of health care workers [1-4]. Shortage of healthcare workers threatens the sustainability of health care systems and negatively affects the achievement of newly launched Sustainable Development Goals (SDGs) in many countries [5, 6]. Sub Saharan Africa is

\footnotetext{
* Correspondence: bvumbwe.tm@mzuni.ac.mw

${ }^{1}$ Faculty of Health Sciences, Mzuzu University, P/ Bag 201, Luwinga, Mzuzu, Malawi

Full list of author information is available at the end of the article
}

worst hit region with a shortfall of more than 600,000 nurses needed to scale up priority interventions [7]. The Lancet Commission and the Global Health Workforce Alliance reported that professional education has generally not kept up the pace of health care challenges [8-10]. The commission noted challenges with health professional education namely; mismatch of competencies to patient and population needs, poor teamwork, persistent gender stratification of professional status, narrow technical focus without broader contextual understanding, predominantly hospital orientation at the expense of primary care and weak leadership to improve health system performance [11]. 
There is a global consensus that nurses and midwives constitute the majority of the global health workforce and the largest health care expenditure [8]. Nurses form the universal access point for almost $90 \%$ of healthcare users [12, 13]. Considering the significance of nursing workforce within the health care systems, efficient production, successful deployment, and ongoing retention are key to ensuring improvements in the functioning and impact of health care system including ensuring universal health coverage $[9,14]$. Efficient production of nurses with relevant competencies remains a critical role of nursing education. Improvements in nursing and midwifery education are recognized as essential in increasing workforce numbers and enhancing the quality of health care and health systems.

Traditionally, nursing and midwifery education has been offered at stand-alone training institutions with more emphasis of production of lower level cadre. Many countries including Malawi, Zambia, Kenya, Zimbabwe still have majority of their nurses at technician level than registered nurse level. However, nursing and midwifery education in Africa has shown signs of development over the past two decades. World Health Organization [15] reported that many countries have now including Masters or Doctoral levels studies in their programs. Nursing colleges in many countries are affiliating their programmes to universities. The Geneva Declaration of the SIDIEF adopted in 2012 urges Francophone countries to introduce university education system for nurses and make undergraduate programme an entry requirement for the nursing profession [16]. Similarly, the Plan of action for Scaling Up Quality Nursing and Midwifery Education and Practice for the African Region 2012 - 2022 provides a framework for WHO member states to improve nursing and midwifery education and training and produce well trained nurses and midwives [17].

However, literature still report lack of necessary competencies among graduates due to lack of strategic leadership to drive transformation [9], unresponsive curricula $[18,19]$, shortage of nursing faculty and shortage of teaching and learning resources resulting into inadequate productive capacity of training institutions. Globally, nursing education continues to experience underinvestment, static and rigid curriculum, lack of inter-professional preparation of nurses and lack of coordinated collaboration and support from stakeholders.

The Plan of Action for Scaling up Quality Nursing and Midwifery Education and Practice for the African Region 2012 - 2022 provided a framework for scale up of nurses and midwives in the region. The purpose of this study was to review literature on status of nursing education in Sub Saharan Africa to inform development of a model for improvement of quality, quantity and relevance of nursing education at local level.

\section{Methods}

The researchers were informed by the works of Whittemore and Knafl [20] which has five stages; problem identification, literature search, data evaluation, data analysis and presentation.

\section{Problem identification}

The research problem emanated from a Norwegian Church Aid (NCA) funded National Nursing Education Research Conference and anecdotal notes from nursing education stakeholders who identified shortage of nursing workforce and growing concerns of poor quality of nursing care because of inefficiencies in the nursing education system. The review was guided by the following research questions: what is the status of nursing education in Sub Saharan Africa, and what are the solutions or innovations being taken to improve nursing education?

\section{Literature search}

A search of PubMed, MEDLINE, Academic search complete, health sources on EBCSOhost and Google scholar was conducted using the key words; nursing education, challenges, solutions, innovations AND Africa. The inclusion criteria for electronic records included primary source and peer reviewed reports on nursing education in Sub Saharan Africa. The review included literature from 2012 to 2016 to capture what has been reported during the period after the Plan of action for Scaling up Quality Nursing and Midwifery Education and Practice for the African Region 2012 2022. Peer reviewed records were targeted to ensure integrity of findings because they already have a level of scrutiny. The review also included a search of grey literature as well as extensive consultation with nursing education experts to identify relevant documents. Key stakeholders including nurse educators, nursing education policy makers were individually approached to voluntarily provide material they knew would be relevant including program documents, project reports and progress reports on nursing education. The process of the integrative review is presented in Fig. 1.

\section{Data evaluation}

Records were evaluated for their authenticity, methodological quality and informational value. A structured data extraction and quality appraisal checklist was utilized on each record for information extraction based on the Critical Appraisal Skills programme Checklist. Initially records were selected based on their titles. Abstracts of selected titles were analysed to assess their relevance to the study question. Only abstracts that 


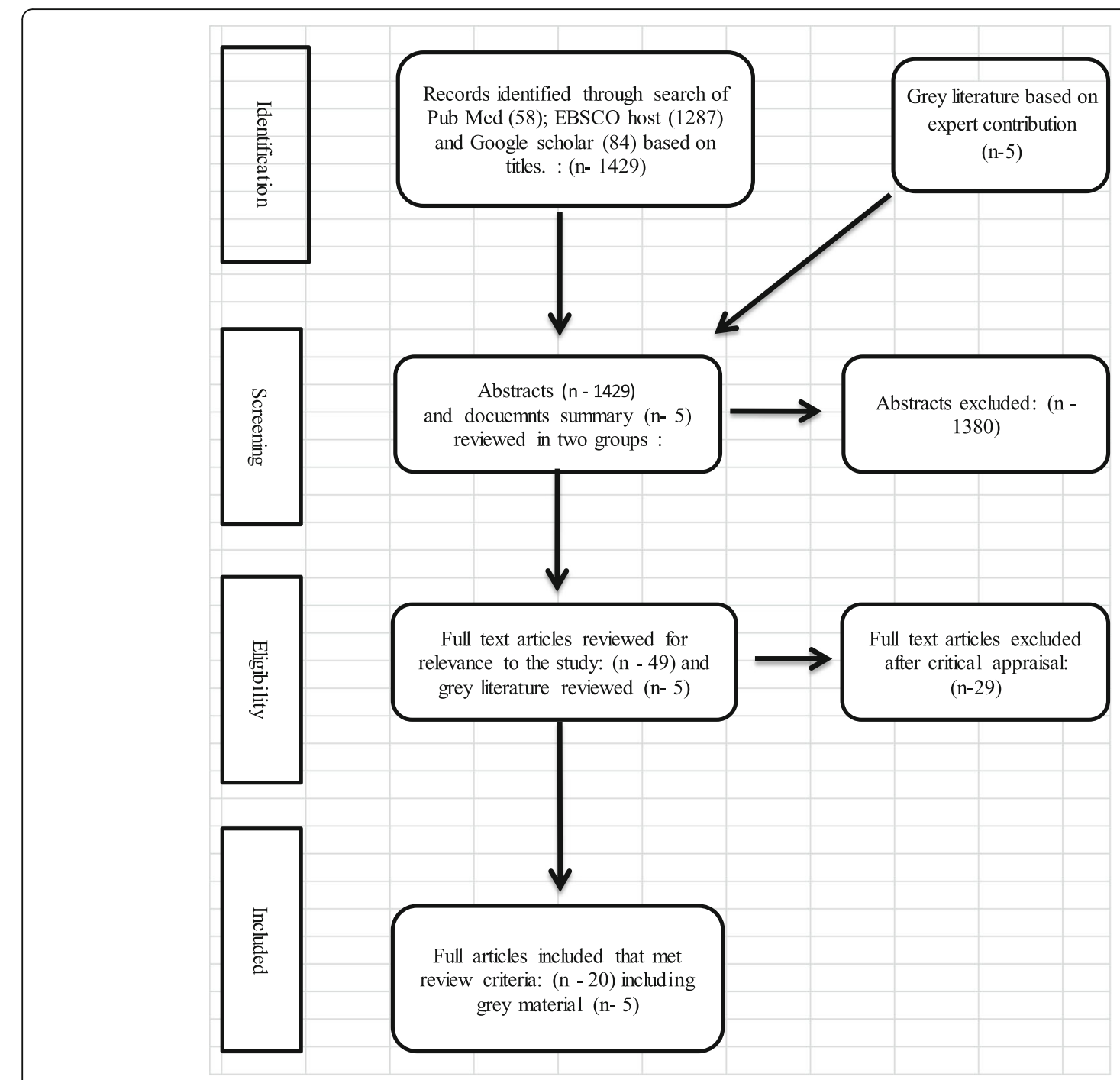

Fig. 1 Process of review

addressed nursing education challenges and solutions in Africa after 2012 were subjected to a full text review. Full text records that did not meet the appraisal process were excluded from the review. Relevant bibliographies from the identified records were also reviewed.

\section{Data analysis}

Thematic analysis was used to analyse data. Data was extracted and coded into manageable framework. This was then displayed to convert extracted data from individual sources into a display that assembles around particular variables or subgroups. Extracted data was compared item by item so that similar data was categorised and grouped together. An iterative process of examining data displays to facilitate distinction of patterns, themes, variations and relationships was done using a comparison method. Conclusions were then drawn from the data. To ensure reliability of the review, the articles and the appraisal forms were independently reviewed by two colleagues. Findings from the researchers and the independent evaluators were compared and discussions were held to reach an agreement.

\section{Results}

The search conducted yielded a total of 1434 records. One thousand two hundred and eighty seven (1287) records were obtained from EBSCOhost database, 58 records from PubMed and 84 from Google scholar and 5 grey records obtained from experts. One thousand three hundred and eighty (1380) abstracts were excluded either because they addressed nursing education outside Sub Saharan Africa or addressed education of health professions in general. Twenty nine (29) full text reports were excluded from the study because they neither 
addressed the challenges nor the solutions of nursing education. Majority of the records addressed perceptions and experiences of nursing students with the nursing training. Finally, twenty (20) records and five (5) grey material were finally included in the review (Table 1).

Six themes emerged from the review namely; curriculum reforms, professional regulation, transformative teaching strategies, collaboration and partnership, capacity building and infrastructure and resources.

\section{Theme 1: Curriculum reforms}

Health care reforms alter the environment in which nurses and other health care workers practice. The review found that in Sub Saharan Africa, emphasis on primary care, emerging of new health challenges, increasing burden of disease significantly demand need for curriculum reforms [21-23]. Mthembu et al. [22] reported that reforms in curricula are necessary to ensure that nursing education produces graduates who influence the quality of the health care system and are relevant to the needs of the population.

Mtshali and Gwele [21] developed a middle range model that would guide the practice of community based education in basic nursing education in South Africa. This curriculum reform in nursing education reported community based education as relevant, responsive education and education for social justice that consciously and deliberately socialize health delivery towards primary health care. We also found that countries within Sub Saharan Africa are prioritizing curriculum reforms from content driven curriculum to competence based curriculum that are responsive to the primary health care [23]. We also found that prevalence of chronic illnesses and co-morbidities that are emerging demands an inter-professional approach and collaboration to manage health [24].

\section{Theme 2: Profession regulation}

Within the changing face of nursing education, key issues in Sub Saharan Africa related to professional regulation include notions of specialist and advanced practice, accountability and autonomy, competence, supervision, continuing education and delegation [25]. McCarthy et al. [25] highlighted that nursing education should complement, advocate and lend technical support to regulatory bodies as regulatory frameworks change due to health care adaptation. The review highlighted that strengthening nursing councils and professional associations helps to improve regulatory activities. Licensure, accreditation, continuing professional development, and scope of practice influence the quality of care provided by the nursing workforce as well as pre-service education program [26].

\section{Theme 3: Transformative teaching strategies}

Appiagyei et al. [27] observed that congestions of students in clinical sites will demand innovative ways to train the growing numbers. As student populations and methods of learning continue to increase in diversity, nurse educators and administrators must be flexible and responsive with effective and innovative solutions to complex market demands. The review found that innovative approaches to teaching and learning are significant for teaching future professions [28]. The complexity of health care demands requires critical thinking as well as competencies that are relevant to these demands. Thus demands for the use of innovative methods of teaching that engage students as active learners, continue to grow. Technology facilitates students' exposure to clinical scenarios that they would normally not encounter in their normal clinical setting [29-31].

\section{Theme 4: Collaboration and partnerships}

We found that the complexity of healthcare demands and practice environment require a coordinated and collaborative approach to training of health professionals including nurses. However, the review show that nurses' engagement in policy making is still complex and contested [32]. Evidence based practice requires decisions about healthcare based on best available, current, valid and relevant evidence. Goosby and von Zinkernagel [33] highlighted that partnerships form a strong foundation for planning and delivery of evidence based health services.

We found that the changing learning environment, competition for learning opportunities and limitations in terms of clinical support pose challenges for professional nurses to perform their multifaceted role [34]. Professional nurses play dual roles of service delivery and clinical teaching and mentoring. Careful planning of students learning experiences is imperative to ensure that students get maximum benefits from their training. Middleton et al. [35] reported that current reforms in nursing education demands sharing of knowledge and information. National and regional networks increase opportunities for sharing best practice in nursing.

\section{Themes 5: Capacity building}

Challenges facing nursing education in Sub Saharan Africa demands strong committed leadership to see mutual goals and strategic contribution and effective use of resources [36]. Building management capacity of nursing training institutions is one strategy that various countries have put in place to ensure adequate and quality education of nurses to strengthen their weak healthcare system. Nursing education operates within a complex environment which has to constantly be put under vigorous evaluation in order to encourage innovations that will 
Table 1 Summary of records reviewed

\begin{tabular}{|c|c|c|c|}
\hline Author and year & Country & Tittle & Contribution to nursing education \\
\hline $\begin{array}{l}\text { Middleton, L., Howard, A, } \\
\text { Dohrn, J, Von Zinkernagel, } \\
\text { D. et al., } 2014\end{array}$ & Sub Saharan & $\begin{array}{l}\text { The Nursing Education Partnership } \\
\text { Initiative (NEPI): Innovations in nursing } \\
\text { and midwifery education. }\end{array}$ & $\begin{array}{l}\text { Building on existing country leadership and } \\
\text { government planning to increase the number } \\
\text { and competencies of new nurses entering the } \\
\text { profession. Country-level leadership, support for } \\
\text { faculty workforce development and key } \\
\text { educational processes and practices, and scaling } \\
\text { up of proven educational methods and } \\
\text { interventions at nursing educational institutions } \\
\text { are key to ensuring sustainability and will help } \\
\text { to achieve priority health goals for the countries } \\
\text { of this region. }\end{array}$ \\
\hline
\end{tabular}

Mthembu, S., Mtshali, N., $\quad$ South Africa Frantz, J. 2014

Goosby, E.P, von Zinkernagel, D. 2014

Jooste, K. \& Jasper, M. 2012

South Africa

Armstrong, S. \& Rispel, L. 2015

South Africa

Adejumo, O., Fakude, L. \& Linda, N., 2014

Marchi-Alves, L.M. Ventura, A., Trevizan, M.A., Mazzo, A. et al. 2013
Contextual determinants for communitybased learning programmes in nursing education in South Africa

The Medical and Nursing Education Partnership Initiatives.
Community Based Learning has emerged as a political instrument that has influenced not only a change in the country's health system but has responded to the needs of the South African population at large

The MEPI and NEPI focus on strengthening learning institutions is central to the vision for expanding the pool of health professionals to meet the full range of a country's health needs. A robust network of exchange between education institutions and training facilities, both within and across countries, is transforming the quality of medical and nursing education and augmenting a platform for research opportunities for faculty and clinicians, which also serves as an incentive to retain professionals in the country.

Different role players are involved in critical issues regarding the management and education of nursing in South Africa. Nurse managers are central to the success of service redesign, delivery and education. Nurse managers need to influence policy decisions regarding nursing service design and delivery, and the education required to prepare the next generation of practitioners for these new services.

Social accountability, which is an essential component of transformative education, necessitates that attention be paid to the issues of governance, responsive curricula, educator preparedness, and appropriate student recruitment and selection

Concerns raised included issues about the facilitation role of the teacher; the role of the student; curriculum alignment; assessment methods; and the role of the environment in case-based teaching and learning settings.

Lack of infrastructure, absence of trained human resources experts, bureaucratic problems to regularize the schools and lack of material resources hinder improvements. Public health education policies need to be established in Angola, including action guidelines that permit effective nursing activities. Professional education institutions need further regularizations and nurses need to be acknowledged as key elements for the qualitative enhancement of health services in the country.

A collaborative model is presented as a potential solution to advance graduate nursing. Four major constituents are identified including hospitals and agencies, communities of interest, Kenyan universities and international education partners. Each has a part to play 
Table 1 Summary of records reviewed (Continued)

\begin{tabular}{lll}
\hline Author and year & Country & Tittle \\
\hline & \\
& \\
& \\
McCarthy, C.F., Voss, J., & East, Central, and & Nursing and midwifery regulatory \\
Salmon, M.E., Gross, J.M., & Southern Africa & reform in East, Central, and Southern \\
Kelley, MA. \& Riley,P., 2013 & & Africa: a survey of key stakeholders,
\end{tabular}

Kelley, M.A. \& Riley, P.L, 2013

Daniels, F.M., Linda, N.S.,

Bimray, P. \& Sharps, P., 2014

South Africa

Effect of increased student enrolment for a Bachelor of Nursing programme on health care service delivery.
Wilson, L.L., Somerall, D., Theus, L., Rankin, S., Ngoma, C. \& Chimwaza, A., 2014
Malawi, Zambia

Enhancing global health and education in Malawi, Zambia, and the United States through an inter-professional global health exchange program

Development of a simulation and skills centre in East Africa: a RwandanCanadian partnership.

Using a task analysis to strengthen nursing and midwifery pre-service education in Malawi

Wasili, R., Langdon, F., Levine, R.

Mondiwa, M., Bateganya, M.

\& MacLachlan, E, 2015

Rwanda

Ntakiyiruta G, Mukwesi C, Whynot, S. \& Brindley, P., 2014

Jacob, S., Holman, J., Msolomba, R., Malawi
Kurth, A., Jacobs, S., Squires, A

Rwanda

Sliney, A., Davis, Stalls.

\& Portillo, C. 2016

Mtshali, N.G. \& Gwele, N.S., 2016

South Africa

Botma, Y., 2014

Bell, S.A., Rominski, S., Bam,V.,

Donkor, E. \& Lori, J., 2013

Kiarie, J., Farquhar, C., Redfield, R., Kenya

Bosire, K., Nduti., Mwanda, W.,

M'Imunya, J. \& Kibwage, I., 2015
Contribution to nursing education

including contributions to information, communication of opinion and expertise, money and support, infrastructure and in-kind resources. Distance education is cost-effective and will help in building capacity at various levels of nursing including leadership in clinical practice, teaching, administration and research.

Information regarding effectively engaging leaders in regulatory reform by clarifying their roles, responsibilities, and activities regarding regulation overall as well as their specific perspectives on task shifting and pre-service reform.

The changing learning environment, competition for learning opportunities and limitations in terms of clinical support posed challenges for professional nurses to perform their multifaceted role which includes clinical teaching and mentoring, and affected service delivery. Therefore, careful planning of students' learning experiences in both theory and practice is imperative to ensure that teaching and learning and service delivery are not negatively affected

Program promoted inter-professional and cross-cultural understanding; fostered development of long-term sustainable partnerships between health professionals and educators in Zambia and the US; and created increased awareness and use of resources for global health education

Developed an adaptable model for simulation and skills centre development in low-resources settings.

Using task analysis, the identified gaps in clinical training and faculty supervision of students. The task analysis provided a robust approach to curriculum revision through identifying key content gaps. Other countries might consider adopting this approach to improving the content and relevancy of nursing and midwifery syllabi and curricula.

The World Health Organization endorses task sharing to ensure universal health coverage in HIV and maternal health, which requires an investment in nursing education, retention, and professional growth opportunities.

The input from the community enhances the relevance of the curriculum to the priority needs of the surrounding community. It also ensures that the CBE curriculum is dynamic and is based on the present, because of the changes taking place in the community.

Changing content driven curriculum to competence based curriculum improved training on nurses with a primary care focus

Faculty and infrastructure shortages are common issues in nursing education and workforce expansion, these issues are compounded by high rates of preventable disease and injury.

The study suggested innovation building capacity of healthcare workers and students through the eBNM program. Students felt they had more opportunities to practice clinical skills, closer mentoring, and closer interactions with 
Table 1 Summary of records reviewed (Continued)

\begin{tabular}{|c|c|c|c|}
\hline Author and year & Country & Tittle & Contribution to nursing education \\
\hline & & & $\begin{array}{l}\text { patients at the at the non-tertiary facilities than } \\
\text { at the tertiary hospital. Health workers at the } \\
\text { non-tertiary hospitals also reported improved } \\
\text { quality of patient care, increased job satisfaction, } \\
\text { and greater interest in research. County } \\
\text { hospitals have retained employees and the } \\
\text { nurses are upgrading their skills without losing } \\
\text { income. }\end{array}$ \\
\hline $\begin{array}{l}\text { Blaauw, D., Ditlopo, P. } \\
\text { \& Rispel, L. } 2014\end{array}$ & South Africa & $\begin{array}{l}\text { Nursing education reform in South Africa - } \\
\text { lessons from a policy analysis study }\end{array}$ & $\begin{array}{l}\text { The study found significant weaknesses in the } \\
\text { policy capacity of the main institutions } \\
\text { responsible for the leadership and governance } \\
\text { of nursing in South Africa, which will need to } \\
\text { be addressed if important nursing education } \\
\text { reforms are to be realised }\end{array}$ \\
\hline $\begin{array}{l}\text { Appiagyei, A.A. Kiriinya, R.N., } \\
\text { Gross, J.M., Wambua, D.N., } \\
\text { Oywer, E.O., Kamenju, } \\
\text { A.K., Higgins, M.K., Riley, P.L. } \\
\text { \& Rogers, M.F. } 2014\end{array}$ & Kenya & $\begin{array}{l}\text { Informing the scale-up of Kenya's nursing } \\
\text { workforce: a mixed methods study of factors } \\
\text { affecting pre-service training capacity and } \\
\text { production }\end{array}$ & $\begin{array}{l}\text { To scale-up the nursing workforce in Kenya, } \\
\text { concurrent investments in expanding the } \\
\text { number of student nurse clinical placement } \\
\text { sites, utilizing alternate forms of skills training, } \\
\text { hiring more faculty and clinical instructors, and } \\
\text { expanding the dormitory and classroom space } \\
\text { to accommodate new students are needed to } \\
\text { ensure that increases in student enrolment are } \\
\text { not at the cost of quality nursing education. }\end{array}$ \\
\hline
\end{tabular}

allow flexibility and effective advancement. ICAP through the Global Nurse capacity Building Program (GNCBP) in six Sub Saharan African countries embarked on building capacity of faculty in nursing education [35, 37].

The complex environment in nursing education demands that academic managers, leaders and players continually monitor the ever- evolving, complex system of the professional tripartite: nursing education, research and practice. Nursing leaders have been challenged to spearhead a successful translation of scientific knowledge that links nursing education to professional practice in the delivery of high quality health care. Jooste and Jasper [38] reported that nurse managers need to influence policy decisions regarding nursing services design and delivery.

Capacity building also surrounds around the issue of faculty ability to prepare a generation of relevant graduates [35, 37]. The review noted that to improve the quality and quantity of nursing, it is necessary to increase the number of nursing faculty and clinical educators who have both expertise in nursing care and commensurate education.

\section{Theme 6: Infrastructure and resources}

We found that lack of infrastructure, absence of trained human resources experts and lack of material resources posed big challenges to nursing education among Sub Saharan African countries $[39,40]$. With the continuing growth in the world's population and the growing disease burden, there is a critical need for increased numbers of qualified health-care personnel and increasingly more efficient healthcare systems. The review shows that the shortage of nurses and midwives has led to increased student enrolment in most countries [34, 39]. Increase in student enrolment has resulted in a strained clinical learning environment, competition for learning opportunities among students [35]. We found that infrastructure investment will facilitate better quality education [39]. The strategy involved providing infrastructure development for the nursing training institutions to accommodate more students and to provide student training fees.

\section{Discussion}

This integrative review has attempted to synthesize relevant published work on nursing education in Africa and made recommendations towards improving the quality, quantity and relevance of nursing education in Su Saharan Africa. Despite the reported severe shortage and maldistribution of nurses between and within countries, nurses remain the single largest available group of available health workers. This positions nurses to be global leaders in driving the quality of health care delivery especially in low -resource settings [41]. Numerous literature report a very significant relationship between nursing and patient safety, patient satisfaction and quality care [42-44]. However, nursing education programs have failed to produce the required graduates who are responsive to the local health policies and programs [45] and the needs of the health care users [46-48].

\section{Curriculum reforms}

A curriculum is at the heart of every educational enterprise [49]. The change in the global health care landscape is putting much pressure for reforms on how 
the health care workforce practices. Forbes and Hickey [50] highlighted four themes within the need for curriculum reform namely incorporating safety and quality in nursing education, re-designing conceptual frameworks, strategies to address content laden curricula and teaching using alternative pedagogies. Jacobs et al. [51] used a task analysis to reform curriculum identified gaps in clinical teaching and faculty supervision. Task analysis provided a robust approach to curriculum revising through identifying content gaps. The healthcare system in Sub Saharan Africa is getting more complex. Demand for adequate and quality teamwork among stakeholders in increasing. Approaches that transform systems and encourage the move away from the traditional focus on tertiary care hospitals to initiatives that foster community engagement are needed.

Nursing plays a key role in the coordination and integration of care and services from other providers [52]. Reforms that embrace inter-professional education will help to remove challenges that come about between professions and this facilitates coordinated care [53]. Liaw et al. [54] supports that inter-professional learning is essential to enhance team collaboration and communication necessary for patient safety and effective healthcare. Therefore, curriculum reform that enhances relevance of nursing programs within multidisciplinary teams and inter-professional collaboration is very significant in Sub Saharan Africa.

\section{Profession regulation}

Nursing as a profession has a unique system of rules an principles to regulate its members and demonstrate its responsibility to society [55]. The changing healthcare landscape such as an ageing society, double burden of disease with an emerging burden of non-communicable diseases, coupled with shortage of nursing specialist cadres in remote areas, the gap between healthcare supply and demand, task shifting and the perception that nurses and midwives do not work to their full potential, is necessitating changes in the scope of practice frameworks [56, 57].

International Council of Nurses [58] identified fundamental responsibilities of nurses to promote health, prevent illness, restore health and alleviate suffering. These responsibilities deal with challenges of determining the scope of professional nursing practice. Schluter et al. [59] argue that the changing pattern of healthcare delivery ultimately leads to a reconsideration on how nurses manage their work in line with associated legislation. Many countries in Sub Saharan Africa have regulatory nursing bodies which are responsible for developing and implementing a regulatory framework. However, several study across the region reported that regulatory bodies do not always have sufficient capacity and resources to face reform demands $[9,60]$.

\section{Transformative teaching strategies}

Many health professional training programs have mostly maintained classroom teaching. These short term lectures and seminars have proved not to be effective in diversifying skills md competencies of health workers including nurses [9]. The review indicates that Sub Saharan Countries have increased healthcare training intakes to solve the shortage of human resource crisis. This has led to congestion of students in clinical sites. Increased intakes demand innovative ways to train these growing numbers. King [61] reported that further expansion of distance education is an innovative and cost effective way of advancing nursing and midwifery in Sub Saharan Africa.

Nurse educators need to examine what they do in and out of classroom to continue to be effective, current and relevant. With the focus on community health demands, training initiatives should prioritise the acquisition of competencies through sustained mentorship and supervision, simulation rather than through ad hoc short term lectures and seminars $[62,63]$.

\section{Collaboration and partnerships}

In some instances a disjuncture between nursing leadership and front line nurses has been reported $[64,65]$. World Health Organization [66] advocates that educational and training institutions should foster and enhance the relational activity, interaction and planning between education, health and other sectors. Both academia and practice have the overall goal of attaining optimal health for their countries.

Careful planning of students learning experiences between academia and practice is imperative to ensure that students get maximum benefits from their training. Current reforms in nursing education demands sharing of knowledge and information. Partnerships between academia and practice can contribute significantly towards a vibrant healthcare system. Effective academic practice partnerships can reduce the theory practice-gap thereby improving patient safety, reducing medical errors, strengthening practice setting and cushioning faculty shortage $[67,68]$. Academia and practice are dissimilar but share values regarding nursing education. An academic practice partnership can therefore be best understood from a view point where the academic and the practice players come together and work collaboratively for a common goal [69]. Implementation of the shared goal should involve specific responsibilities for the educators, hospital administrators, students and the nurse practitioners through a systems approach [70]. 
Academic practice partnerships provide a platform for partners to capitalize on each other's expertise. This also improves access to a broader array of clinical experiences for students. Students receive adequate clinical support that is blended with expertise from both academic knowledge and practice competencies. Evidence supports that mentorship provided by clinical personnel is critical to students' training outcomes [71]. Quality clinical practice outcome is dependent on preparation and willingness of practice partners. Narasimhan et al. [72] noted that lack of mutual planning results in over-expenditure on unimportant activities within the effort to improve quality of nursing education.

\section{Capacity building}

World Health Organization [60] highlighted that significant investment will be required to strengthen educational infrastructure, faculty and staff development, curriculum review and clinical instruction. To improve the quality and quantity of nursing, it is necessary to increase the number of nursing faculty and clinical educators who have both expertise in nursing care and commensurate education. Evidence from South Africa indicated that the education and training system for the health sector has not grown sufficiently to meet health needs and health system requirements. This is in part due to lack of integrated planning between the health and education sectors on the development of health professionals in relation to health care need, and inadequate financing mechanisms for health professional development.

\section{Infrastructure and resources}

Health worker shortage in Sub Saharan Africa is a result of many causes which include past investment shortfalls in pre- service training, international migration, career changes among health workers, premature retirement and morbidity and mortality [7]. Experience shows that despite the increased enrolment in most countries, the number of quality clinical environment has remained the same. The review has highlighted that clinical learning environment is been strained. There is need to deliberately invest in infrastructure both at training institutions and practice levels.

\section{Strengths and limitations of the study}

This review shares useful information for improving nursing education among stakeholders worldwide. The major limitation of the study was that it only focused on literature from Sub Saharan Africa.

\section{Implication for practice}

Nursing and midwifery remains the backbone of the healthcare system worldwide. Continued efforts to improve training of nurses and midwives will ensure improved health outcomes. Effective nursing education will ensure provision of competence based practice among nurses. More research on nursing education will help to improve practice standards in nursing and midwifery.

\section{Conclusion}

The integrated review highlights that majority of countries within Sub Saharan Africa are experiencing common challenges ranging from strained training institutions due to increased enrolments, inadequate faculty capacity, lack of infrastructure and resources, high demand for clinical training sites. To ensure improved quality and quantity of production, developmental partners have increased allocation of financial resources for infrastructure and teaching and learning material. Efforts are being done to expand number of clinical sites, build faculty capacity and increase collaboration with clinical institutions for clinical instructors and mentors. Curriculum reforms are being implemented to reposition the nursing workforce for a competence based approach, community based education and inter-professional training. Clinical simulation and technology based teaching strategies are on the increase to accommodate the demands for new ways of teaching and learning.

\section{Abbreviations \\ HIV/AIDS: Acquired Immunodeficiency Syndrome/ Human Immunodeficiency Virus; NCA: Norwegian Church Aid; SDGs: Sustainable Development Goals}

\section{Acknowledgements}

Thanks go to all nursing students at Mzuzu University who participated in the abstract appraisal during the review.

Funding

Not Applicable

\section{Availability of data and materials}

The datasets used and/or analysed during the current study available from the corresponding author on reasonable request.

\section{Authors' contributions}

TB and NM conceptualized the study, collected and analysed data. Both authors drafted and approved the final manuscript.

Ethics approval and consent to participate

Not Applicable

\section{Consent for publication \\ Not Applicable}

\section{Competing interests}

The authors declare that they have no competing interests

\section{Publisher's Note}

Springer Nature remains neutral with regard to jurisdictional claims in published maps and institutional affiliations.

\section{Author details}

${ }^{1}$ Faculty of Health Sciences, Mzuzu University, P/ Bag 201, Luwinga, Mzuzu, Malawi. ${ }^{2}$ School of Nursing, University of KwaZulu Natal, Durban 4041, Republic of South Africa. 
Received: 24 July 2017 Accepted: 23 January 2018

\section{Published online: 31 January 2018}

\section{References}

1. Mooketsane KS, Phirinyane MB. Health governance in Sub-Saharan Africa. Globl Soc Policy. 2015;15(3):345-8.

2. Negeri KG, Halemariam D. Effect of health development assistance on health status in sub-Saharan Africa. Risk Manag Healthc Policy. 2016;9:33.

3. Akinyemi JO, Chisumpa VH, Odimegwu CO. Household structure, maternal characteristics and childhood mortality in rural sub-Saharan Africa. Rural Remote Health. 2016;16(2):3737.

4. Keino S, Plasqui G, Ettyang G, van den Borne B. Determinants of stunting and overweight among young children and adolescents in sub-Saharan Africa. Food Nutr Bull. 2014;35(2):167-78.

5. Scheffler RM, Tulenko K, et al. The deepening global health workforce crisis: forecasting needs, shortages, and costs for the global strategy on human resources for health (2013-2030). Ann Glob Health. 2016;82(3):510.

6. Tangcharoensathien $\mathrm{V}$, Mills A, Palu T. Accelerating health equity: the key role of universal health coverage in the sustainable development goals. BMC Med. 2015:13:101.

7. Kinfu Y, Dal Poz MR, Mercer H, Evans DB. The health worker shortage in Africa: are enough physicians and nurses being trained? Bull World Health Organ. 2009;87(3):225-30.

8. Global Health Workforce Alliance W. A universal truth: no health without a workforce. Geneva: World Health Organization; 2013.

9. Frenk J, Chen L, Bhutta ZA, Cohen J, Crisp N, Evans T, et al. Health professionals for a new century: transforming education to strengthen health systems in an interdependent world. Lancet. 2010;376(9756):1923-58.

10. Crisp N. A global perspective on the education and training of primary care and public health professionals. London J Prim Care. 2012:4(2):116-9.

11. Frenk J, Chen L, Bhutta ZA, Cohen J, Crisp N, Evans T, et al. Health professionals for a new century: transforming education to strengthen health systems in an interdependent world. Lancet. 2010;376:1923-58.

12. Mosadeghrad A. Factors influencing healthcare service quality. Int J Health Policy Manag. 2014;3(2):77-89.

13. Rich ML, Miller AC, Niyigena P, Franke MF, Niyonzima JB, Socci A, et al. Excellent clinical outcomes and high retention in care among adults in a community-based HIV treatment program in rural Rwanda. J Acquir Immune Defic Syndr. 2012;59(3):e35-42.

14. Institute of Medicine Committee. The future of nursing: leading change, advancing health. Washington (DC): National Academies Press (US). Copyright 2011 by the National Academy of Sciences. All rights reserved; 2011.

15. World Health Organization. Global standards for the initial education of professionals nurses and midwives. Geneva: WHO; 2009. Available from: http://www.who.int/publications

16. SIDIIEF. Declaration in favor of university education for nurses in the Frenchspeaking countries. Geneva; 2012. Available from: https://www.sidiief.org/ wp-content/uploads/Declaration-Geneve-Anglais.pdf. Accessed 15 July 2015.

17. WHO. Plan of action for scaling up Quality Nursing \& Midwifery Education \& practice for the African region 2012 - 2022. Region Office for Africa: WHO; 2012

18. Brown RA, Crookes PA. What are the 'necessary' skills for a newly graduating RN? Results of an Australian survey. BMC Nurs. 2016:15:1-8.

19. Ulrich B, Krozek C, Early S, Ashlock CH, Africa LM, Carman ML. Improving retention, confidence, and competence of new graduate nurses: results from a 10-year longitudinal database. Nursing economic. 2010;28(6):363-76.

20. Whittemore R, Knafl $K$. The integrative review: updated methodology. J Adv Nurs. 2005;52(5):546-53.

21. Mtshali NG, Gwele NS. Community-based nursing education in South Africa: a grounded-middle range theory. J Nurs Educ Pract. 2016;6(2):55.

22. Mthembu S, Mtshali N, Frantz J. Contextual determinants for communitybased learning programmes in nursing education in South Africa. S Afr J High Educ. 2014;28(6):1795-813.

23. Botma Y. How a monster became a princess: curriculum development. S Afr J High Educ. 2014;28(6):1876-93.

24. Wilson LL, Somerall D, Theus L, Rankin S, Ngoma C, Chimwaza A. Enhancing global health and education in Malawi, Zambia, and the United States through an interprofessional global health exchange program. Appl Nurs Res. 2014;27(2):97-103
25. McCarthy CF, Voss J, Salmon ME, Gross JM, Kelley MA, Riley PL. Nursing and midwifery regulatory reform in east, central, and southern Africa: a survey of key stakeholders. Hum Resour Health. 2013;11:29.

26. McCarthy CF, Riley PL. The African health profession regulatory collaborative for nurses and midwives. Hum Resour Health. 2012;10(1):1.

27. Appiagyei AA, Kiriinya RN, Gross JM, Wambua DN, Oywer EO, Kamenju AK, et al. Informing the scale-up of Kenya's nursing workforce: a mixed methods study of factors affecting pre-service training capacity and production. Hum Resour Health. 2014;12:47.

28. Adejumo O, Lorraine F, Linda NS. Revisiting innovative approaches to teaching and learning in nursing programmes: educators' experiences with the use of a case-based teaching approach at a nursing school. 2014

29. Livingston P, Bailey J, Ntakiyiruta G, Mukwesi C, Whynot S, Brindley P. Development of a simulation and skills centre in East Africa: a RwandanCanadian partnership. Pan Afr Med J. 2014;17(1):315.

30. Kiarie JN, Farquhar C, Redfield R, Bosire K, Nduati RW, Mwanda W, et al. Strengthening health systems by integrating health care, medical education, and research: University of Nairobi experience. Acad Med. 2014; 89(8 Suppl):S109-10.

31. Mutea N, Cullen D. Kenya and distance education: a model to advance graduate nursing. Int J Nurs Pract. 2012;18(4):417-22.

32. Armstrong SJ, Rispel LC. Social accountability and nursing education in South Africa. Glob Health Action. 2015;8:27879.

33. Goosby EP, von Zinkernagel D. The medical and nursing education partnership initiatives. Acad Med. 2014;89(8 Suppl):S5-7.

34. Daniels FM, Linda NS, Bimray P, Sharps P. Effect of increased student enrolment for a bachelor of nursing programme on health care service delivery. S Afr J High Educ. 2014;28(6):1750-61.

35. Middleton L, Howard AA, Dohrn J, Von Zinkernagel D, Parham Hopson D, Aranda-Naranjo B, et al. The nursing education partnership initiative (NEPI): innovations in nursing and midwifery education. Acad Med. 2014;89(8 Suppl):S24-8.

36. Blaauw D, Ditlopo P, Rispel LC. Nursing education reform in South Africa lessons from a policy analysis study. Glob Health Action. 2014:7. https://doi. org/10.3402/gha.v7.26401.

37. Kurth AE, Jacob S, Squires AP, Sliney A, Davis S, Stalls $S$, et al. Investing in nurses is a prerequisite for ensuring universal health coverage. J Assoc Nurses AIDS Care. 2016:27(3):344-54.

38. Jooste K, Jasper M. A south African perspective: current position and challenges in health care service management and education in nursing. J Nurs Manag. 2012;20(1):56-64.

39. Bell SA, Rominski S, Bam V, Donkor E, Lori J. An analysis of nursing education in Ghana: priorities for scaling-up the nursing workforce. Nurs Health Sci. 2013;15(2):244-9.

40. Marchi AL, Ventura CA, Trevizan M, Mazzo A, de Godoy S, Mendes IC Challenges for nursing education in Angola: the perception of nurse leaders affiliated with professional education institutions. Hum Resour Health. 2013;11(1):1.

41. Dall TM, Chen YJ, Seifert RF, Maddox PJ, Hogan PF. The economic value of professional nursing. Med Care. 2009;47(1):97-104.

42. Bruyneel L, Li B, Aiken L, Lesaffre E, Van den Heede K, Sermeus W. A multicountry perspective on nurses' tasks below their skill level: reports from domestically trained nurses and foreign trained nurses from developing countries. Int J Nurs Stud. 2013;50(2):202-9.

43. Cho E, Lee N, Kim E, Kim S, Lee K, Park K, et al. Nurse staffing level and overtime associated with patient safety, quality of care, and care left undone in hospitals: a cross-sectional study. Int J Nurs Stud. 2016;60:263-71.

44. You L, Aiken LH, Sloane DM, Liu K, He G, Hu Y, et al. Hospital nursing, care quality, and patient satisfaction: cross-sectional surveys of nurses and patients in hospitals in China and Europe. Int J Nurs Stud. 2013;50(2):154-61.

45. Kaye DK, Muhwezi WW, Kasozi AN, Kijjambu S, Mbalinda SN, Okullo I, et al. Lessons learnt from comprehensive evaluation of community-based education in Uganda: a proposal for an ideal model community-based education for health professional training institutions. BMC Med Educ. 2011;11(1):1.

46. Farsi Z, Dehghan-Nayeri N, Negarandeh R, Broomand S. Nursing profession in Iran: an overview of opportunities and challenges. Jpn J Nurs Sci. 2010;7(1):9-18.

47. Tanner CA. Transforming prelicensure nursing education: preparing the new nurse to meet emerging health care needs. Nurs Educ Perspect. 2010;31(6):347-53. 
48. Kabore I, Bloem J, Etheredge G, Obiero W, Wanless S, Doykos P, et al. The effect of community-based support services on clinical efficacy and health-related quality of life in HIV/AIDS patients in resourcelimited settings in sub-Saharan Africa. AIDS Patient Care STDs. 2010; 24(9):581-94.

49. Karseth B. Curriculum changes and moral issues in nursing education. Nurse Educ Today. 2004;24(8):638-43.

50. Forbes MO, Hickey MT. Curriculum reform in baccalaureate nursing education: review of the literature. Int J Nurs Educ Scholarsh. 2009;6:Article27.

51. Jacob S, Holman J, Msolomba R, Wasili R, Langdon F, Levine R, et al. Using a task analysis to strengthen nursing and midwifery pre-service education in Malawi. Int J Nurs Midwifery. 2015;7(5):84-103.

52. Robson W. Eliminating avoidable harm: time for patient safety to play a bigger part in professional education and practice. Nurse Educ Today. 2014; 34(5):e1-2.

53. Bridges DR, Davidson RA, Odegard PS, Maki IV, Tomkowiak J. Interprofessional collaboration: three best practice models of interprofessional education. Med Educ Online. 2011;16 https://doi.org/10.3402/meo.v16i0.6035.

54. Liaw SY, Zhou WT, Lau TC, Siau C, Chan SW. An interprofessional communication training using simulation to enhance safe care for a deteriorating patient. Nurse Educ Today. 2014;34(2):259-64.

55. Flook DM. The professional nurse and regulation. J PeriAnesth Nurs. 2003; 18(3):160-7.

56. Fairman JA, Rowe JW, Hassmiller S, Shalala DE. Broadening the scope of nursing practice. N Engl J Med. 2011;364(3):193-6.

57. Riegel B, Sullivan-Marx E, Fairman JA. Meeting global needs in primary care with nurse practitioners. Lancet. 2012;380(9840):449-50.

58. International Council of Nurses. The ICN code of ethics for nurses 2012 Available from: http://www.icn.ch/images/stories/documents/about/ icncode_english.pdf. Accessed 15 July 2015.

59. Schluter J, Seaton P, Chaboyer W. Understanding nursing scope of practice: a qualitative study. Int J Nurs Stud. 2011;48(10):1211-22.

60. World Health Organization. Transformative scale up of health professional education: an effort to increase the numbers of health professionals and to strengthen their impact on population health. 2011.

61. King L. Distance education: the solution for nursing and midwifery in Africa? Int Nurs Rev. 2000:47(2):63.

62. Celletti F, Reynolds TA, Wright A, Stoertz A, Dayrit M. Educating a new generation of doctors to improve the health of populations in low-and middle-income countries. PLoS Med. 2011;8(10):e1001108.

63. Körükcü Ö, Kukulu K. Innovation in nursing education. Procedia Soc Behav Sci. 2010;9:369-72

64. Akunja E, Kaseje D, Obago I, Ochieng B. Involvement of hub nurses in HIV policy development: case study of Nyanza Province, Kenya. Res Humanit Soc Sci. 2012;2:124Á34.

65. Shariff $N$, Potgieter E. Extent of east-African nurse leaders' participation in health policy development. Nurs Res Pract. 2012;2012:504697.

66. World Health Organization. WHO guidelines approved by the guidelines review committee. Transforming and scaling up health Professionals' education and training: World Health Organization guidelines 2013. Geneva: WHO; 2013.

67. Murray $T A$, James DC. Evaluation of an academic service partnership using a strategic alliance framework. Nurs Outlook. 2012;60(4):e17-22.

68. Chan EA, Chan K, Liu YJ. A triadic interplay between academics, practitioners and students in the nursing theory and practice dialectic. J Adv Nurs. 2012;68(5):1038-49.

69. Bvumbwe T. Enhancing nursing education via academic-clinical partnership: an integrative review. Int J Nurs Sci. 2016;3(3):314-22.

70. Missal B, Schafer BK, Halm MA, Schaffer MA. A university and health care organization partnership to prepare nurses for evidence-based practice. J Nurs Educ. 2010:49(8):456-61.

71. Lofmark A, Thorkildsen K, Raholm MB, Natvig GK. Nursing students' satisfaction with supervision from preceptors and teachers during clinical practice. Nurse Educ Pract. 2012;12(3):164-9.

72. Narasimhan V, Brown H, Pablos-Mendez A, Adams O, Dussault G, Elzinga G, et al. Responding to the global human resources crisis. Lancet. 2004; 363(9419):1469-72.

\section{Submit your next manuscript to BioMed Central and we will help you at every step:}

- We accept pre-submission inquiries

- Our selector tool helps you to find the most relevant journal

- We provide round the clock customer support

- Convenient online submission

- Thorough peer review

- Inclusion in PubMed and all major indexing services

- Maximum visibility for your research

Submit your manuscript at www.biomedcentral.com/submit
Biomed Central 